Journal of Advanced College of Engineering and Management, Vol. 5, 2019

\title{
ENERGY SCENARIOS OF HOUSEHOLD SECTOR IN PANAUTI MUNICIPALITY FOR SUSTAINABLE DEVELOPMENT AND ENERGY SECURITY
}

\author{
Pramila Dhaubanjar ${ }^{1}$, Amrit Man Nakarmi², Sushil B.Bajracharya ${ }^{3}$ \\ Email Address: Prakritipramila@gmail.com \\ ${ }^{2}$ Professor, DoME, Pulchowk Campus, Institute of Engineering, T.U. \\ ${ }^{3}$ Professor, Department of Architecture, Pulchowk Campus, Institute of Engineering, T.U.
}

\begin{abstract}
This study aims to analyse energy scenarios of residential sector in Panauti Municipality for sustainable energy development and energy security. This study was done by conducting a questionnaire survey, and was supported by secondary data from various sources. Data analysis was carried out with the help of excel and LEAP software. From the results, total energy consumption of Panauti Municipality is $147 \mathrm{TJ}$ in year 2016 with per capita is $4.72 \mathrm{GJ}$ and per capita emission $82 \mathrm{~kg}$. The main fuel for consumption in residential sector is firewood with share $44 \%$ then followed by LPG with $26 \%$ of total energy. Cooking is the most energy intensive end-use, accounting $60 \%$ of total energy consumption, followed by animal feed preparation $28 \%$. It was seen that total electrification in all end-use can reduce energy demand by $57 \%$ and $35 \%$ respectively in AEL and SUD scenario andsaved fuel import cost about NRs.235 million. in year 2050. Using nationally available electricity ensures energy security and has co-benefit of emission reduction.
\end{abstract}

Keywords: Residential energy; Panauti; LEAP; Scenario; Emission

\section{Background}

Nepal'senergy resources are presently classified into three categories: traditional, commercial and alternative. The overall energy consumption of Nepal is largely dominated by the use of traditional energy such as fuel-wood, agricultural residues and animal waste. The total energy consumption of Nepal in the year 2008/09 was about 403 PJ. The energy demand of Nepal is heavily dependent on biomass energy which accounts about $78 \%$ of total energy consumption. Only $12 \%$ of energy consumption is from commercial energy sources such as petroleum and electricity. Petroleum products, which are imported, accounts for about $8 \%$ of the total energy consumed, and electricity represented only $2 \%$ of the total energy consumption in 2010 . It has been observed that the LPG is substituting as a cooking fuel in the urban centres as the consumption growth rate of LPG is about $23 \%$ per annum and followed by electricity with 10 percent (WECS, 2010). In 1996, about $10.8 \%$ of urban households used LPG for cooking purpose and only $0.2 \%$ of rural households used LPG for cooking, however, the rural percent of LPG user has been increased to 6.8\% in 2011 (CBS, 2011). Increasing demand for imported fossil fuels will create a problem of energy scarcity and price rise.

Consumption of traditional and fossil fuels emits local air pollutants such as particulate matter, black carbon, nitrogen dioxide, sulphur dioxide etc. Local air pollution can have serious impacts on environment and human health. The studies by(Pui et al., 2014), (Chowdhury \& Dey, 2016) and (Kamarehie, et al., 2017) found that acute health effects such as cardiovascular and respiratory and mortality and premature death are increased with exposure to $\mathrm{PM}_{2.5}$. Some studies: (Grahame et al., 2014) and (Janssen, et al., 2011) indicates that health effects due exposure are stronger for BC than $\mathrm{PM}_{2.5}$. Indoor air pollution is the major problem in developing countries. Almost 3 billion of the world's poorest people still rely on solid fuels (wood, animal dung, charcoal, crop wastes and coal) burned in inefficient and highly polluting stoves for cooking and heating, currently resulting in some 4 million premature deaths annually among children and adults from respiratory and cardiovascular 
diseases, and cancer (WHO, 2014). The continuing and wide spread use of traditional energy source (fuel wood), as a result of growing population and its dependence has become a major cause for large scale environmental problem such as deforestation, soil erosion, landslide, scarcity of water, decrease in agricultural production etc. Thus, it is essential to develop policy and strategy that would minimize the energy demand, emissions with lowest adverse impact to the environment, health as well as with high co-benefits for the consumer and the nation.

\section{Study area}

Table 1: Background information (CBS, 2011)

Panauti is a relatively small municipality in Kavrepalanchowk district of Bagmati Zone of central Development Region. The municipality lies $32 \mathrm{Km}$ east of Kathmandu and immediately south of Banepa Municipality. It lies at an altitude of $1300-1600 \mathrm{~m}$ with latitude of 850 32' and longitude of 270 38'. The main source of income is agriculture. Potato, paddy, orange, milk etc are the main agricultural products. Besides these people have taken small scale industries, business, animal husbandry as the source of income. Panauti is bordered by Sharada Batase, Shankhupati Chaur VDC and Dhulikhel Municipality on the east; Kusdevi, Mahendrajyoti VDC on the west; Janagal VDC and Banepa Municipality on the north; and Kalati Danda, Chalal Ganesthan and

\begin{tabular}{|l|c|}
\hline District & Kavre Palanchwok \\
\hline No. of wards & 13 \\
\hline Total area & 31.73 sq.km \\
\hline Population(2011) & 27358 \\
\hline No. of household & 5943 \\
\hline Growth rate & $2.72 \%$ \\
\hline Household size & 4.6 \\
\hline Population Density & 862.21 \\
\hline
\end{tabular}
Balthali VDC on the south.

\section{Methodology}

\subsection{Primary data survey}

As per the Central Bureau of Statistics-2011, there are about 5943 households in Panauti Municipality. It is impossible to collect the energy consumption data from all the households. So, suitable sample size was taken to determine the total energy consumption for the analysis. The sample size was calculated using the following formula (Krejice \& Morgan, 1970).

$$
\mathrm{S}=\frac{\mathrm{X} 2 \mathrm{NP}(1-\mathrm{P})}{d 2(N-1)+\mathrm{X} 2 \mathrm{P}(1-\mathrm{P})}
$$

Where,

$\mathrm{S}=$ required sample size

$\mathrm{X}^{2}=$ table value of chi-square for 1 degree of freedom at the desired confidence level

$\mathrm{N}=$ population size

$\mathrm{P}=$ population proportion

$\mathrm{d}=$ the degree of accuracy expressed as a proportion.

It consists of 13 wards and about 5943 households. With the confidence level of $95 \%$ and the degree of accuracy $10 \%$, the sample size would be 94 households. After the determination of sample size, the numbers of households were determined on the basis of proportion of population distribution in each ward. So that data collection would cover households from all wards of Panauti Municipality. 


\subsection{Data analysis}

The collected data were in the questionnaire sheet in hardcopy, which was time consuming to find the actual situation of energy consumption. So, the collected household energy data were compiled in Microsoft Excel so that it would be easy to handle and readable and also would be easy to input data in the LEAP for data analysis.

\subsection{LEAP Model}

LEAP (Long-range Energy Alternatives Planning System) is highly flexible in terms of the type of data and degree of customization. LEAP follows an end use, demand driven approach, which means that the analysis starts from the end use of energy. The demand program divides the society in a hierarchical tree structure of many levels: sectors, sub-sectors, end -uses and devices. It can be used to account for both energy sector and non-energy sector greenhouse gas (GHG) emission sources and sinks. LEAP can also be used to analyse emissions of local and regional air pollutants, making it wellsuited to studies of the climate co-benefits of local air pollution reduction. LEAP is capable of displaying an "energy balance" for a particular modelled system, which includes information such as energy consumption, conversion, and production according to fuel type. The program can also generate a cost-benefit summary report, which provides a comparative overview of costs and benefits of different scenarios relative to the baseline scenario.

The base year data was developed from the primary survey data. The energy intensity and other required parameters which are required for leap model calculated from primary data. Energy model for residential sector of Panauti municipality was developed. The residential sector was comprised of 7 end-use services: cooking, lighting, water heating, room heating, room cooling, electric appliances and animal feed preparation and a total of 22 enduse technologies based on fuel types such as firewood, LPG, electricity etc. The technologicaldata have been obtained from technology database ofLEAP, other relevant sources and market study. The cost for demand technologies, transformation and resources are taken from the study by Rajbhandari \& Nakarmi (2014) with discount rate of $6 \%$.

\subsection{Scenario Description}

\section{Business-as-Usual Scenario (BAU)}

Business as usual scenario is the base line scenario which assumes that the past trends will continue in the near future year and no additional measurement will be put into practice. Thus the share of each demand technology in the energy supply in future years will be same as in the base year. In this scenario, population growth rate and GDP growth rate will be same as base year.

\section{All Electrification scenario (AEL)}

All Electrification Scenario follows the principle objectives of sustainable energy for all (SE4ALL) that promote access of electricity for all. In this scenario, there will be access of uninterrupted electricity supply policy. This scenario promotes the potential of electricity generation from hydropower and solar PV. The inefficient fuel as well as fossil fuel will gradually replace by electricity. The population growth and GDP growth rate will be same as Business-as-Usual scenario.

\section{Sustainable Development Scenario (SUD)}

Sustainable Development scenario also follows the principle objectives of sustainable energy for all that promoted electricity and solar energy for sustainable development. Traditional and fossil fuels will gradually replace by clean fuels: electricity and solar in order to reduce GHGs and local air pollutants emission. The population growth will be same as in BAU scenario. This scenario is developed in order to make comparable with the energy consumption at all with that of households in 
Kathmandu valley and to meet tier 5 as in "Beyond Connection: Energy Access Redefined"(ESMAP, 2015).

\section{Results and Discussion}

\section{Energy Consumption Pattern in 2016}

The total energy demand of residential sector of Panauti Municipality was 147 TJ. About 108 TJ of energy was derived from renewable source which includes traditional biomass and about 39TJ of energy was from non-renewable sources. Figure 1 shows the final energy consumption on Panauti Municipality by fuel type. It shows that firewood accounts a major share of energy consumed (44\%) followed by LPG (26\%), and then agricultural residue (15\%). The renewable energy solar accounts only $2 \%$ of share, biogas accounts $4 \%$ and electricity accounts $9 \%$ of share. The little amount of kerosene and wax was used for lighting purpose during grid electricity is not available.

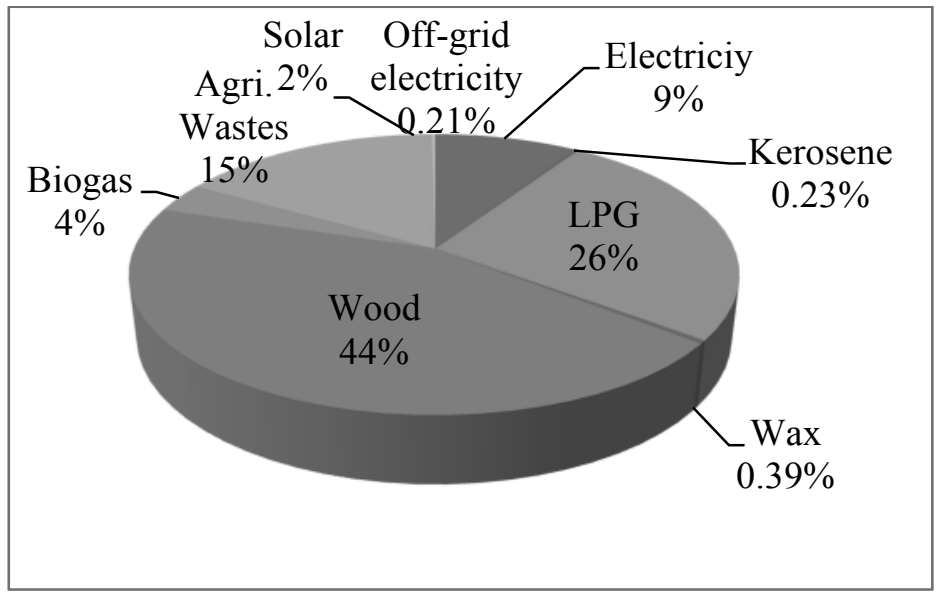

Fig 1: Final energy share by fuel type

Figure 2 shows the final energy demand by endues type. It is found that cooking is the most energy intensive endues which accounts for $60 \%$ of total energy demand. It is followed by animalfeed preparation (28\%), other electric appliances $(5 \%)$, water heating (3\%) and lighting (3\%). Room heating and room cooling accounts less than $1 \%$ of total energy consumed. About $42 \%$ energy for cooking was fulfilled by LPG then followed by firewood (39\%).

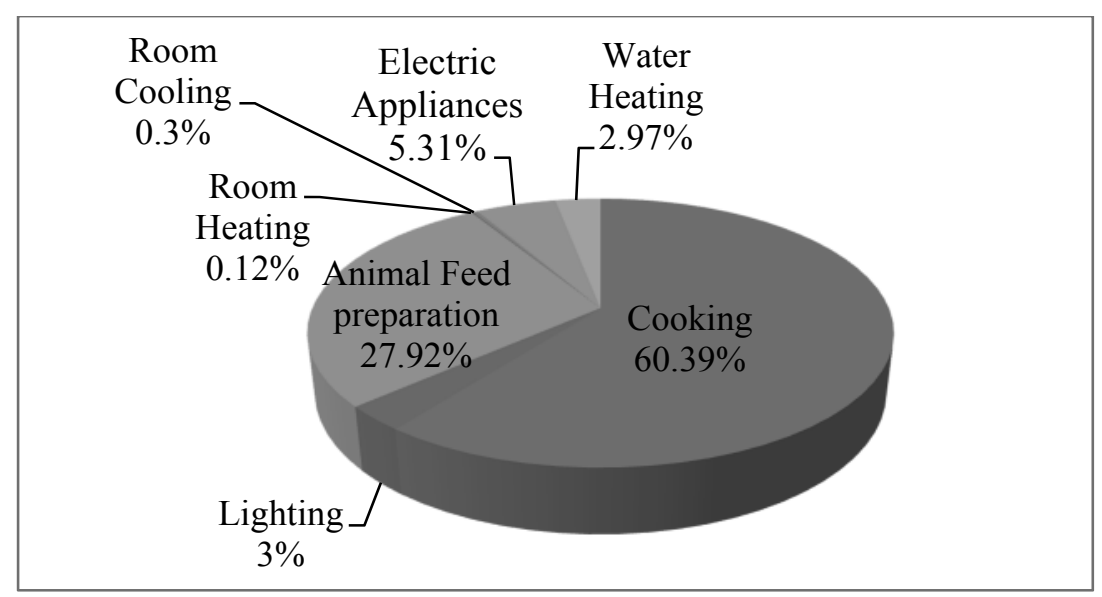

Fig 2: Final energy demand by end-use 


\section{Scenario Analysis}

\subsection{Final energy demand}

The final energy demand for the base year was $147 \mathrm{TJ}$ and will increase at the rate of $2.7 \%$ annually to 367 TJ. The per capita energy consumption was 4.7 GJ in base year. This per capita energy consumption was lesser than per capita energy consumption in Dhulikhel Municipality i.e. 5.05 GJ (Shrestha et al., 2016) This difference is due to economic condition and secondary data on which they are based on assumptions in the study period. Figure 3 compares final energy demand of all three scenarios along with the energy mix in each interval for each scenario. There will be reduction in final energy demand in AEL and SUD scenarios in 2050 because of energy transition to highly efficient energy i.e. electricity. In AEL scenario, energy demand will decreasedat the rate of 3.4\% from 2016 to 2030 and then will increase at the rate of $2.7 \%$. This is due to fuel switching from low efficient fuel to high efficient energy.

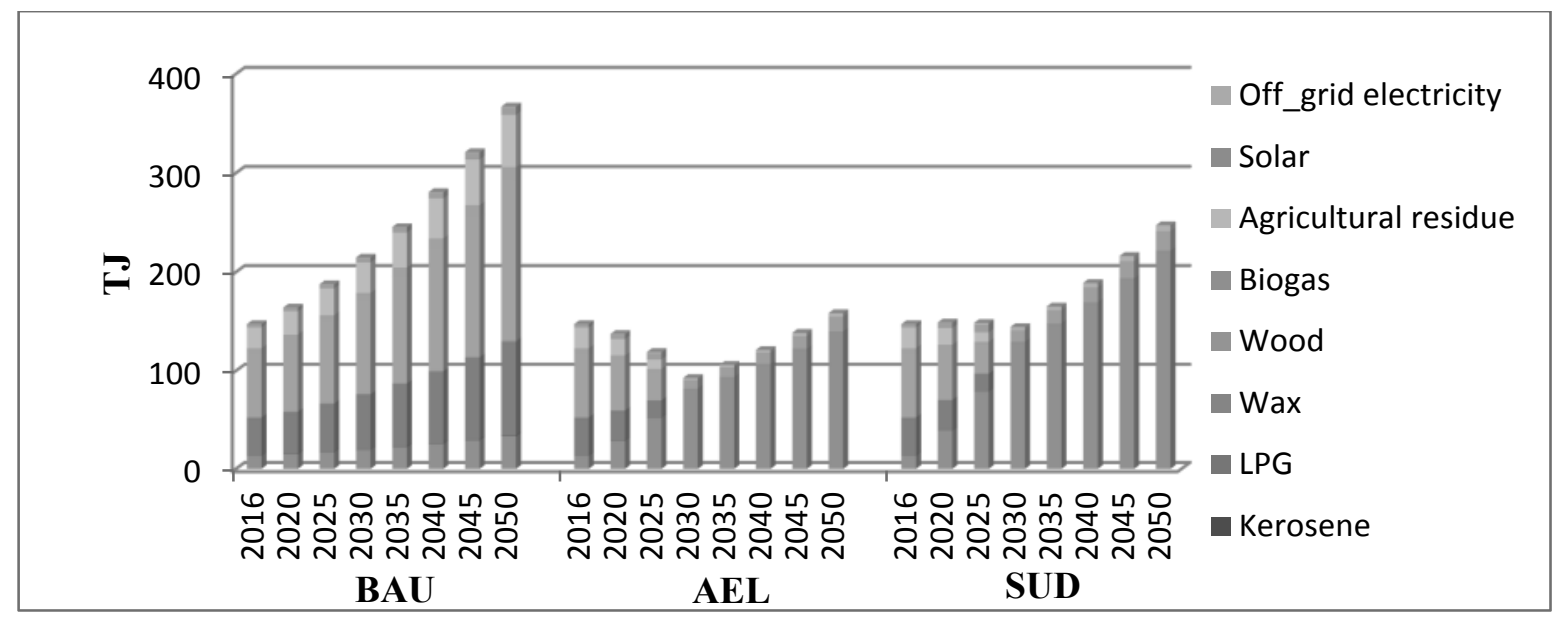

Fig 3: Final energy demand

\subsection{Power plant requirement}

Figure 4 shows total power plant requirements in each scenario. The power supply is supported by Panauti Hydropower with installed capacity of $2.6 \mathrm{MW}$ which is not sufficient to fulfil the electricity demand of Panauti municipality. Electricity demand will be fulfilled by importing electricity from national grid. The power supply is also supported by off-grid solar PV for lighting purpose. Power plant i.e. hydro power plant requirement is highest in SUD scenario and lowest in BAU scenario. Power plant requirement at the end of the study period will be about $3 \mathrm{MW}, 9 \mathrm{MW}$ and $16 \mathrm{MW}$ respectively in BAU, AEL and SUD scenarios. In other to fulfil the electricity demand, the power plant will have to develop at the rate of $2.72 \%$ annually for BAU scenario. Similarly in AEL scenario, power plant requirement will increase at the rate of 13\% annually from the year 2016 to 2030 and from the year 2030 to 2050 power plant requirement will increased at the rate of $2.7 \%$ whereas in SUD scenario, growth rate will be about $18 \%$ annually from the year 2016 to 2030 and from the year 2030 to 2050 power plant requirement will increased at the rate of $2.72 \%$. Before the year 2030 , energy consumption depends on multiple source of energy i.e. traditional and fossil fuel and from the year 2030 it will depends on clean energy i.e. electricity and solar. 


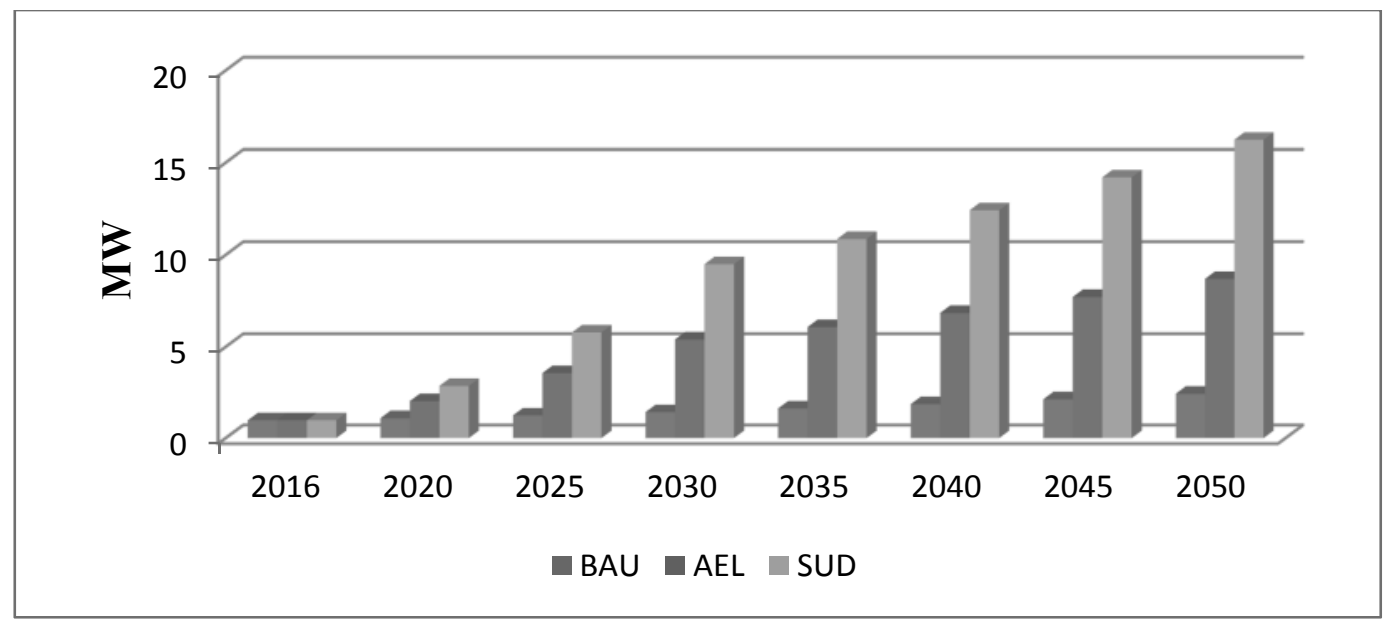

Fig 4: Power Plant Requirement

\subsection{GHGs emission}

Figure 5 shows the GHGs emissions for each scenario. It can be seen that GHGs emission in BAU scenario grows with the rate of $2.7 \%$ whereas other two scenarios gradually reduce to negligible by the year 2030. The per capita GHG emission in BAU scenario is about $82 \mathrm{~kg}$. This shows gradual phase out of traditional and fossil fuel by electricity and solar reduces the emissions of GHGs and also local air pollutants. Reduction in emissions of GHGs and local air pollutants means reduction in environmental impact as well as human health impacts. AEL and SUD scenarios are favourable to environment and also human health.

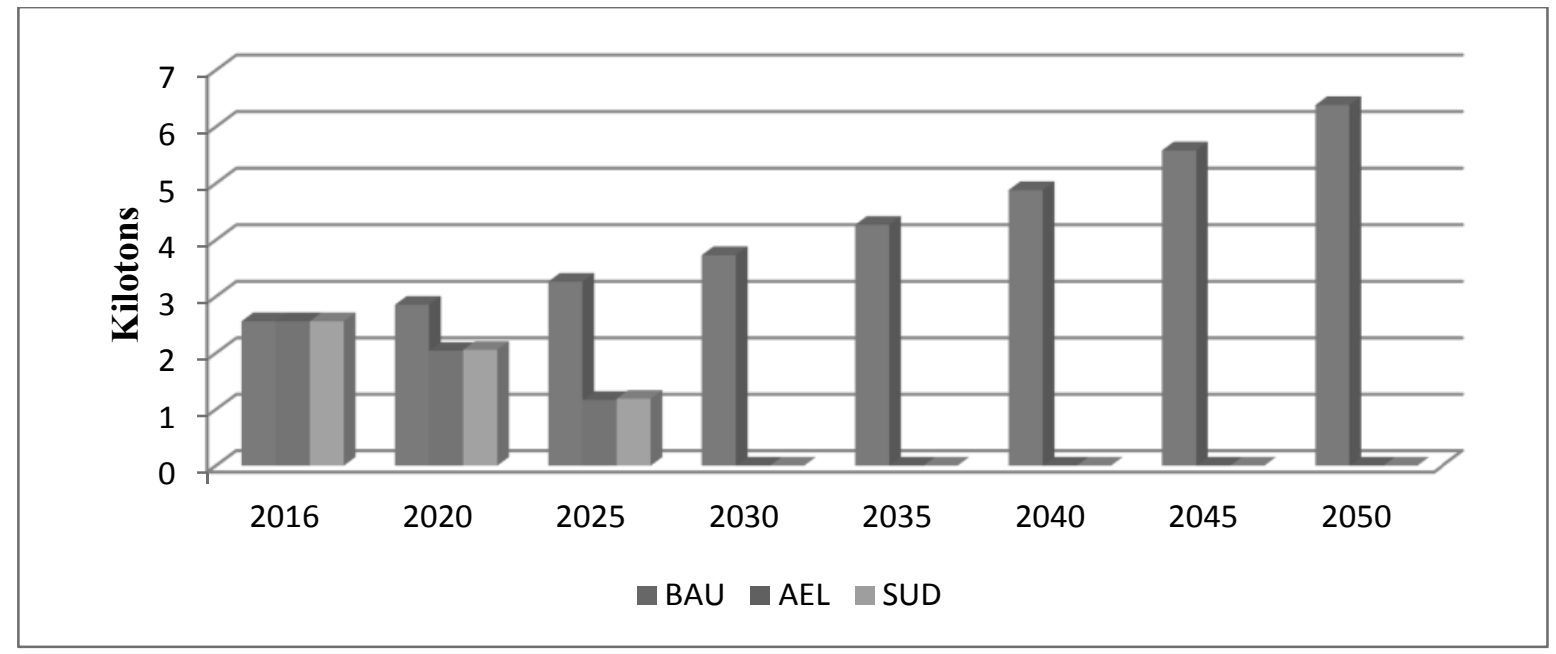

Fig 5: GHGs emission

As gradual phase out of traditional and fossil fuel in AEL and SUD by the year 2030, all GHGs emission in BAU scenario will reduce by the year 2030 and follows to the year 2050. There will be about same reduction in emission in SUD and AEL scenarios. Thus, the rate of emission saving in both scenarios will be same i.e. $2.72 \%$ annually. And impacts of GHGs to the environment and human health can be reduced by energy transition to electricity.

\section{$5.4 \quad \mathbf{P M}_{2.5}$ emission}

Figure 6 shows the emission of $\mathrm{PM}_{2.5}$. Gradual phase out of traditional and fossil fuel in AEL and SUD by the year 2030 also reduce $\mathrm{PM}_{2.5}$ emission from about 30MT to negligible by the year 2030 in SUD and AEL scenarios. In BAU scenario, $\mathrm{PM}_{2.5}$ emission will increase at the rate of $2.7 \%$ annually 
and reached to $74 \mathrm{MT}$ in year 2050. And impacts of $\mathrm{PM}_{2.5}$ to human health can be reduced by energy transition to electricity.

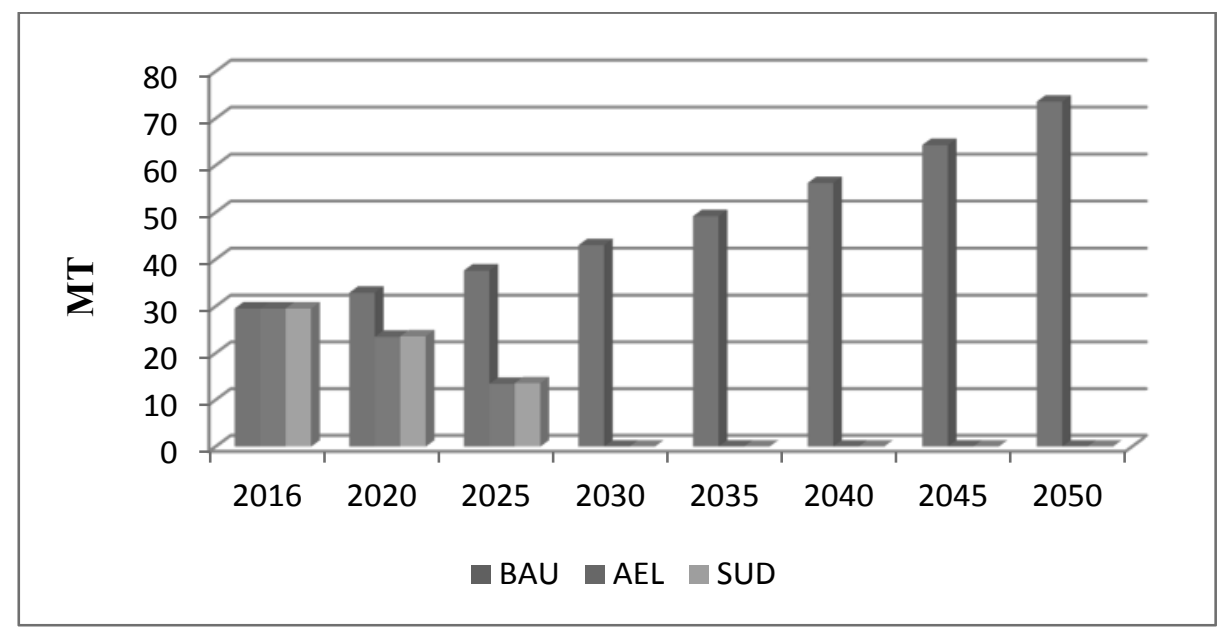

Fig 6: PM2.5 emission

\subsection{Black carbon emission}

Figure 6 shows the emission of black carbon. Gradual phase out of traditional and fossil fuel in AEL and SUD by the year 2030 also reduce black carbon emission from about 4MT to negligible by the year 2030 in SUD and AEL scenarios. In BAU scenario, black carbon emission will increase at the rate of $2.7 \%$ annually and reached to $11 \mathrm{MT}$ in year 2050 .

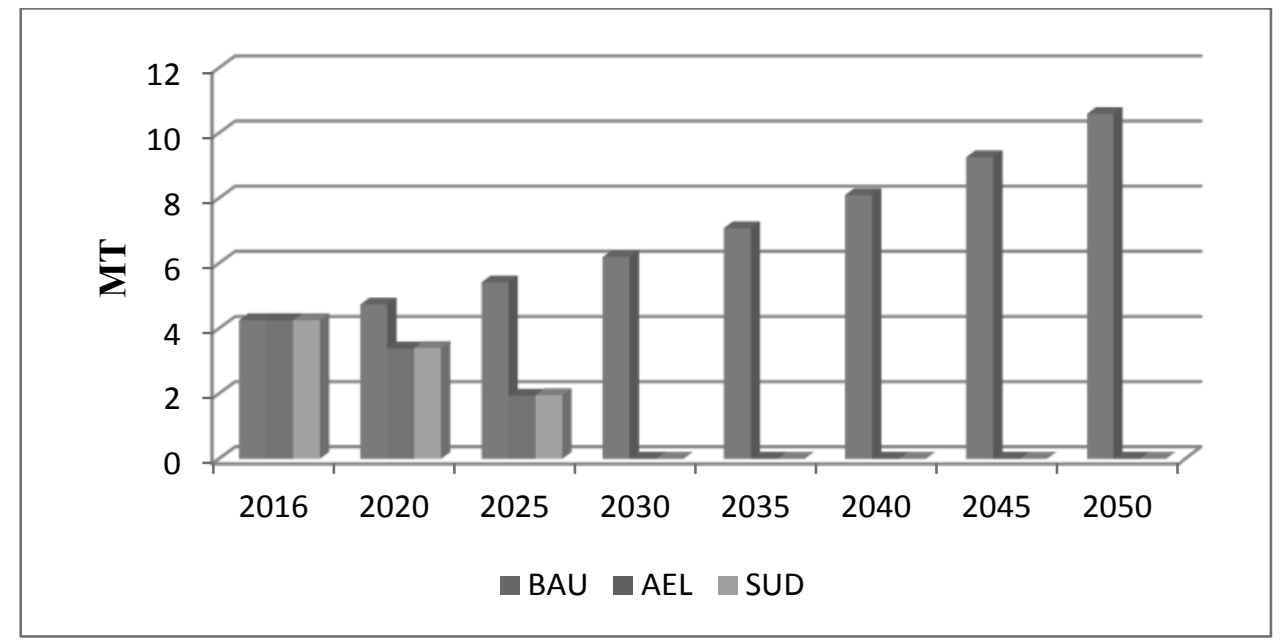

Fig 7: Black carbon emission

\subsection{Fuel Import Cost}

Figure 6 shows the fuel import cost for LPG and kerosene import. Nepal is fully dependent on imported petroleum fuels from neighbouring countries. Thus, energy security has always been a major concern. In order to secure energy security, it is necessary of proper policy and technology intervention. In this study import of fossil fuel: LPG and kerosene are considered. Total fuel import cost in base year is aboutNRs. 44 million. In BAU scenario fuel import cost increases at the rate of $5 \%$ annually reach to NRs. 235 million in 2050. Whereas in AEL and SUD scenario fuel import cost will be negligible in year 2030. This is due to fuel switching to indigenous electricity and solar energy. 


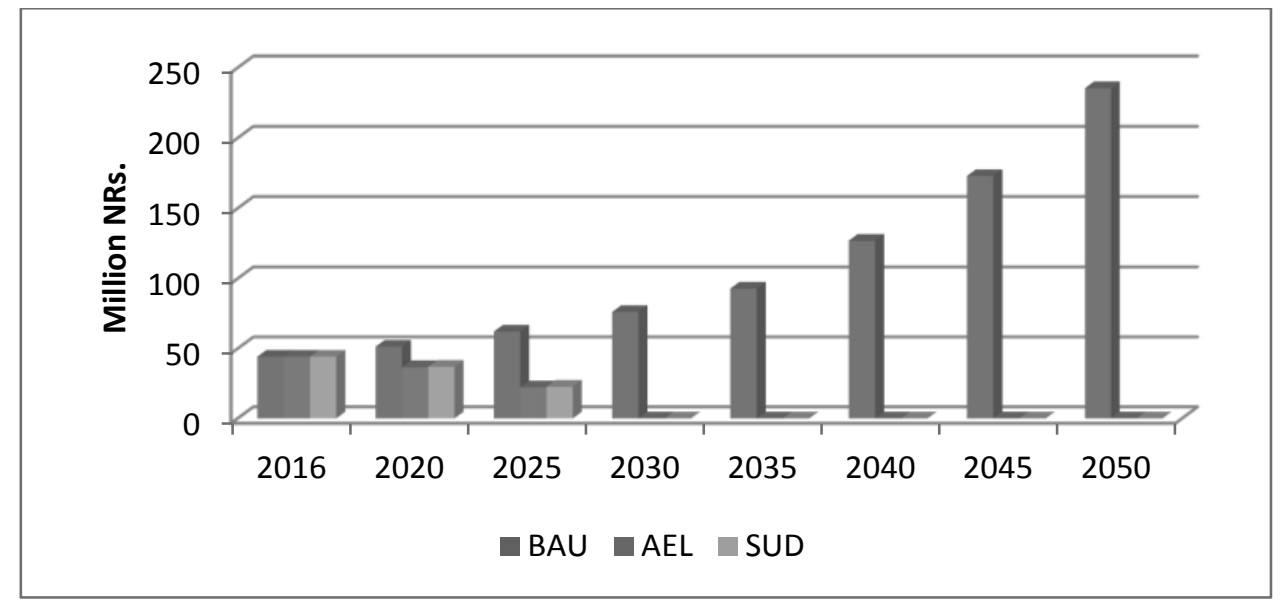

Fig 8: Fuel import cost

Figure 7 shows the fuel import cost saving for each scenario. It can be seen that both scenario: AEL and SUD scenarios can save same amount of saving i.e. about NRs. 76 million in 2030 and gradually increase to about NRs.235 million in 2050. Due to sudden fuel switching, the overall fuel import cost can be saved. The fuel import cost saving can be invested in hydropower development and solar power plant to fulfill the demand. Use of nationally available resources provide energy security and has co-benefit of emission reduction.

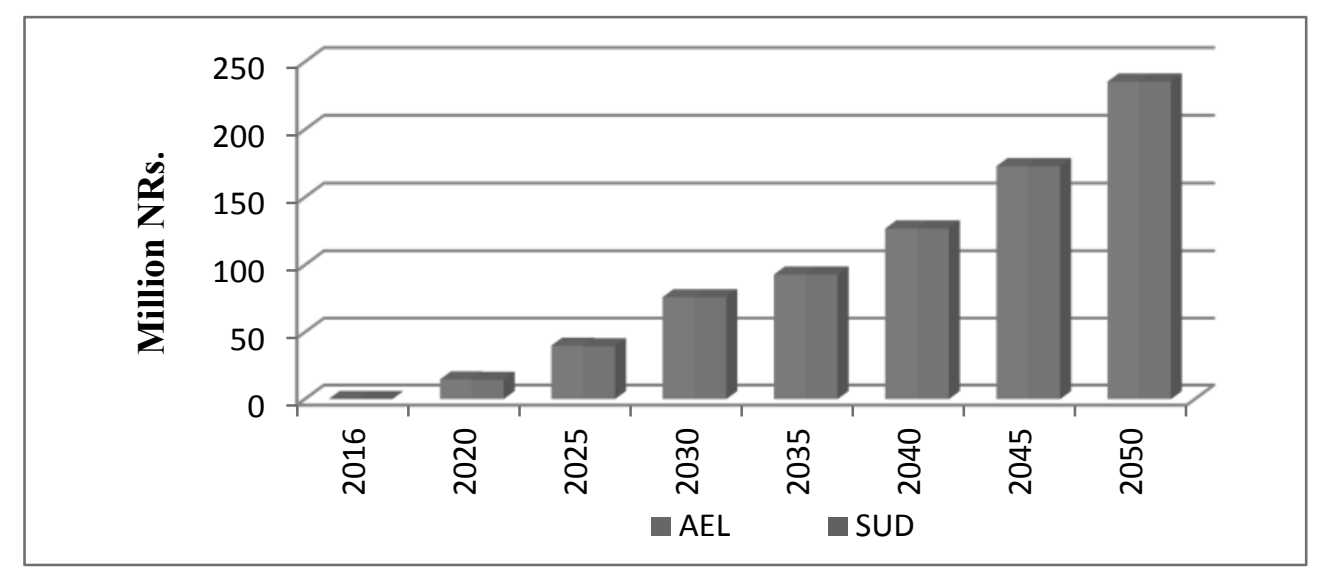

Fig 9:Fuel import cost saving

\subsection{Cost Analysis of Scenario}

The demand costs in all scenarios are high compared to BAU scenario. Also transformation costs in all scenarios are higher than BAU scenario because of increase in the electricity demand. In scenarios: AEL and SUD, the resources production and imports show less amounts, because of fuel switching to electricity. The most important part of cost benefit analysis is net present value (NPV), which is one of the criteria to select the scenario. The NPV is lower in AEL \& SUD scenarios, which means that, both of the scenarios are economically viable. Table 2 shows the summary of cost of each scenario. Form NPV value, it is found that AEL scenario is most economically viable with NPV value NRs. 5668 million. 
Table 2: Cost Analysis of scenario

\begin{tabular}{|l|c|c|c|}
\hline Cost in million NRs. & BAU & AEL & SUD \\
\hline Demand & $\mathbf{3 , 8 2 3}$ & $\mathbf{4 , 1 9 5}$ & $\mathbf{4 , 2 0 6}$ \\
\hline Residential sector & 3,823 & 4,195 & 4,206 \\
\hline Transformation & $\mathbf{1 3 6}$ & $\mathbf{7 6 7}$ & $\mathbf{1 , 4 1 8}$ \\
\hline Grid electricity & 136 & 767 & 1,416 \\
\hline Off-grid electricity & 0.00 & 0.01 & 2 \\
\hline Resources & $\mathbf{2 , 5 0 0}$ & $\mathbf{6 9 8}$ & $\mathbf{7 0 2}$ \\
\hline Production & 1,321 & 403 & 405 \\
\hline Imports & 1,179 & 295 & 297 \\
\hline Environmental Externalities & 28 & 8 & 9 \\
\hline Discount rate & $6 \%$ & $6 \%$ & $6 \%$ \\
\hline Net Present Value & $\mathbf{6 , 4 8 6}$ & $\mathbf{5 , 6 6 8}$ & $\mathbf{6 , 3 3 5}$ \\
\hline GHG Emissions (million Tones CO2e) & 0.15 & 0.02 & 0.02 \\
\hline
\end{tabular}

\section{Conclusion}

Energy plays a central role in the global economy. All household require energy services to meet basic human needs and to serve productive processes. The total energy consumption of Panauti Municipality is $147 \mathrm{TJ}$ in year 2016. The average energy consumption per capita is 4.72 GJ. The main fuel for consumption in residential sector is firewood with share of $44 \%$ of total energy then followed by LPG with $26 \%$ of total energy. Cooking is the most energy intensive end use, accounting for about $60 \%$ of total energy consumption.

It was seen that total electrification in all endues can reduce energy demand by $58 \%$ and eliminate emission in year 2050 AEL whereas in SUD, it can reduced 35\% energy demand. And also can saved fuel import cost about NRs.235 million. at the end of study period in both AEL and SUD. This saving can be invested for developing indigenous energy generation such as hydropower plant which will increase energy security. From cost-benefit analysis, net present value for SUD scenario is higher than in AEL scenario. By fuel switching to electricity and solar energy, electricity consumption per household in AEL scenario is about 2,400 $\mathrm{KWH}$, which meets only tier-4 and in SUD scenario is about 3,770 KWh, which meets tier-5 of report ESMAP (2015).

It was found that total GHG emission in base year was about 2.6 kilotons. The per capita GHG emission was about $82 \mathrm{~kg}$. The local air pollutants: $\mathrm{PM}_{2.5}$ was about $30 \mathrm{MT}$ and that of black carbon was about 4 MT. From the fuel transition, emission of GHG, $\mathrm{PM}_{2.5}$ and black carbon will be reduced to negligible by the year 2030 in both AEL and SUD scenarios. 


\section{Recommendations}

A study has some shortcomings and limitations due to various factors. During the study certain assumptions were made. With the reference to this study, further studies could be done. Some of which are as follows:

- There are other major energy consuming sector such as commercial, transport, agricultural and non energy sectors. For further analysis these sectors can be undertaken.

- Environmental impact such as temperature rise, crop loss and health impact from emissions can be undertaken for further study.

- It was found that about $80 \%$ of household were with load capacity of $5 \mathrm{~A}$. Induction heaters have different types of wattage. Induction heaters with medium burner have wattage of 1500$1800 \mathrm{KW}$. So, if induction cooker runs in power output mode of $1500 \mathrm{~W}$, then the current consumed will be $1500 / 220 \mathrm{X} 0.8=5.45 \mathrm{~A}$. So for policy intervention such as induction heater for cooking purpose, it is necessary to change load capacity to $15 \mathrm{~A}$.

\section{Reference}

1. $\quad$ CBS. (2011). "Nepal Living Standards Survey". Kathmandu: Central Bureau of Statistics National Planning Commission Secretariat, Government of Nepal.

2. Chowdhury, S., \& Dey, S. (2016). "Cause-specific premature death from ambient PM2.5 exposure in India: Estimate adjusted for baseline mortality". Environment International, 91, 283-290.

3. ESMAP. (2015). "Beyond ConneCtions energy Access Redefned. Washington DC": World Bank.

4. Grahame, T. J., Klemm, R., \& Schlesinger, R. B. (2014). "Public health and components of particulate matter: The changing assessment of black carbon". Journal of the Air \& Waste Management Association, 64(6), 620-640.

5. Heaps, C. G. (2016). "Long-range Energy Alternatives Planning (LEAP) system. Somerville", MA, USA: [Software version: 2017.11.0] Stockholm Environment Institute.

6. Janssen, N. A., Hoek, G., Lawson, M. S., Fischer, P., Bree, L. v., Brink, H. t., et al. (2011). "Black Carbon as an Additional Indicator of the Adverse Health Effects of Airborne Particles Compared with PM10 and PM2.5". Environmental Health Perspectives, 119, 1691-1699.

7. Kamarehie, B., Ghaderpoori, M., Jafari, A., Karami, M., Mohammadi, A., Azarshab, K., et al. (2017)."Estimation of health effects (morbidity and mortality) attributed to PM10 and PM2.5 exposure using an Air Quality model in Bukan city, from 2015-2016 exposure using air quality model". Environmental Health Engineering and Management, 4(3), 137-142.

8. Krejice, R. V., \& Morgan, D. W. (1970). "Determing Sample Size for Research Avtivities. Educational and Psychological Measurement" , 607-610.

9. Pui, D. Y., Zuo, Z., \& Chen, S.-C. C. (2014). PM2.5 in China: "Measurements, sources, visibility and health effects, and mitigation". Particuology, 13, 1-26.

10. Rajbhandari, U. S., \& Nakarmi, A. (2014). "Energy Consumption and Scenario Analysis of Residential Sector Using Optimization Model - A Case of Kathmandu Valley". Proceedings of IOE Graduate Conference , 476-483. 
11. Shrestha, A., Ghimire, A., Khanal, K., \& Phuyal, S. (2016). "Study of Current Energy Consumption of Dhulikhel Municipality". Proceedings of the International Symposium on Current Research in Hydraulic Turbines .

12. WECS. (2010). "Energy Sector Synopsis Report 2010". Kathmandu, Nepal: Water and Energy Commission Secretariat (WECS).

13. WHO. (2014). "WHO guidelines for indoor air quality: household fuel combustion". Geneva, Switzerland: World Health Organization 2014. 